\title{
OS ROAD MOVIES NA PRODUÇÃO CINEMATO- GRÁFICA DOS EUA: O CASO DO FILME AS VI- NHAS DA IRA (1940)
}

\section{THE ROAD MOVIES IN THE USA'S CINEMATOGRAPHIC PRODUCTION : THE GRAPES OF WRATH MOVIE CASE} (1940)

Resumo: O presente artigo visa propor uma análise fílmica em relação com a história, inserida dentro do campo historiográfico da história cultural, abordando o tema da formação do gênero cinematográfico road movie e da história dos Estados Unidos da América na década de 1930 e início de 1940. A partir da análise de caso de As Vinhas da Ira, pretende-se analisar o significado da mobilidade, do automóvel e da viagem neste filme e a relação destes elementos com o proposto período históri$\mathrm{co}^{2}$.

Palavras-chave: História e Cinema; Análise Fílmica; Representações; road movie; As Vinhas da Ira; modernidade;

Abstract: This article aims to propose a film analysis in relation to history, inserted into the historiographical field of cultural history, addressing the issue of formation of cinematic road movie genre and history of the United States in the 1930s and early 1940s. From the case analysis of the Grapes of Wrath, we intend to analyze the meaning of mobility, vehicle and travel in this film and the relationship of these elements with the historical moment.

${ }^{1}$ Graduanda em História - Bacharelado com Licenciatura pela Universidade Federal do Paraná. flavia.rmelo@ @otmail.com. Currículo Lattes:

http://lattes.cnpq.br/8817803783991750.

${ }^{2} \mathrm{O}$ presente artigo é um desdobramento de uma pesquisa de cunho monográfico intitulada "Família Norte-Americana e Miséria: análise das representações da pobreza e da instituição familiar em As Vinhas da Ira, de 1940." Professor orientador Dr. Pedro Plaza Pinto. UFPR, junho de 2014. 
Keywords: History and cinema; film analysis; representations; road movie; The Grapes of Wrath; modernity

\section{Introdução}

Discussões historiográficas sobre a relação entre os campos do cinema e da história vêm tendo desde a década de 1980 um lugar mais receptivo nos espaços acadêmicos, sendo tal relação reconhecida como uma nova perspectiva de estudo sobre o passado (LAGNY, 1997). A capacidade do audiovisual de expressar uma realidade histórica, seja por meio de sua representação fílmica, seja por meio da análise do filme em relação ao seu tempo, legitimou a recepção de produções audiovisuais como representantes da história cultural e como objetos para se analisar as noções de história na contemporaneidade (OLIVEIRA, 2008).

Ao longo da história do cinema, seu desenvolvimento enquanto arte e indústria gerou a categorização de gêneros cinematográficos, levando em consideração características estéticas e elementos narrativos específicos em cada caso (BERNARDET, 2006). Jacques Aumont e Michel Marie frisam como a concepção de gênero em cinema sempre teve considerações hesitantes para sua definição. Entretanto, uma convenção é a de que gêneros só tem existência se são reconhecidos pela crítica e público, sendo, portanto, elementos históricos, derivados da evolução comercial das artes (AUMONT; MARIE, 2003: 142).

Um gênero de cinema que aloca filmes de grande sucesso e tem um público cativo é o gênero de road movie, o filme de estrada. A compreensão dos filmes enquanto pertencente a este gênero considera como objetos centrais para sua categorização principalmente três elementos, 
que são a estrada, o veículo e uma jornada - isto é, uma viagem (PAIVA, 2011). Sendo estes o conjunto de objetos do gênero road movie, devemos reiterar que a concepção de gêneros fílmicos deve ser sempre considerada com o devido reconhecimento de que fronteiras nem sempre estáveis e de identidades não inatas são balizas de qualquer gênero cinematográfico.

Walter Moser aponta o filme As Vinhas da Ira como um dos predecessores deste gênero historicamente, sendo o mesmo essencialmente norte-americano e com seus maiores representantes no estilo nas décadas de 1960 e 1970, com filmes como Easy Rider (Dennis Hopper, 1969) e Bonnie and Clyde (Arthur Penn,1967) (MOSER, 2008: 15). Moser defende que a periodização do gênero não é tão fechada, pois se os filmes forem categorizados enquanto suas características narrativas, estéticas, e sobre os elementos de composição da narrativa - a estrada, o veículo e a ideia de viagem, no presente caso-, a periodização fica mais flexível. Por esta razão, pode-se compreender e colocar As Vinhas da Ira como um road movie, pois este compartilha de todos os elementos e categorizações próprias do gênero, mesmo que, em suma, seu roteiro não dê à família Joad as mesmas motivações para que eles peguem a estrada que Wyatt e Billy têm em Easy Rider.

\section{O cinema e a história: relações para o estudo}

O historiador tem a posição de selecionar e dar sentido ao passado (seu objeto de estudo), o que também acontece para o analista fílmico. Através de uma metodologia de análise particular e eleita pelo analista, 
ele aborda determinados aspectos de um filme e os investiga, elencando elementos específicos de um filme - como a família, a mulher ou trabalho, por exemplo - para estabelecer um estudo da forma como este objeto se apresenta no discurso fílmico e interpretando esta apresentação. Assim, análises fílmicas devem se utilizar da produção historiográfica para suas apreciações, pois a compreensão do contexto sociohistórico em que o filme foi produzido é um dos elementos críticos que o analista deve usar para corroborar seu estudo e sua interpretação (AUMONT; MARIE, 2004).

Jacques Aumont e Michel Marie consideram que "tal como não existe uma teoria unificada do cinema, também não existe qualquer método universal de análise do filme"(AUMONT; MARIE, 2004: 235). A principal explicação para a singularidade deste tipo de estudo que interpreta filmes a partir de sua análise, e neste caso relação com a história, é a de que cada análise se adéqua ao seu objeto, ao filme com que se preocupa. Uma análise fílmica não é senão a racionalização de fenômenos observados nos filmes, e cada analista deve "habituar-se à ideia de que precisará mais ou menos construir o seu próprio modelo de análise, unicamente válido para o filme ou o fragmento do filme que analisa", "(AUMONT; MARIE, 2004: 17). É com esta premissa que buscamos relacionar o gênero road movie e a história através de As Vinhas da Ira, buscando com sua contextualização com gênero uma análise de sua estrutura narrativa, considerando este enquanto produto de um período que contêm representações sociais e construções imagéticas intrínsecas e contemporâneas à seu tempo. Assim, a análise deste filme visa tanger 
as mudanças na instituição familiar na sociedade norte-americana das décadas de 1930 e 1940 considerando o significado do deslocamento e do automóvel, típicos do road movie, como elementos de análise.

\section{O que é cinema?}

Uma primeira teorização sobre o que é cinema, deve sem dúvidas, historicizar sua criação. A importância de pontuar cronologicamente o advento do cinema não se deve somente a uma proposta de escrita da história do cinema - a sua criação, desenvolvimento tecnológico e estético - mas também a um intento de elencar quais outras características no cinema, que não apenas sua evolução técnica, devem ser consideradas em um estudo.

A primeira exibição pública paga do cinematógrafo foi promovida pelos irmãos Lumiére no Café Paris, em 28 de dezembro de 1885. Jean-Claude Bernadet pontua como a compreensão de movimento e a impressão de realidade que o cinema projeta são características marcantes e determinantes para análises audiovisuais (BERNARDET, 2006). A compreensão de que o cinema é um artifício, isto é, uma ilusão e recriação do real, nunca deve ser, como aponta o autor, deixada de lado. É uma teorização que não considera o filme uma recriação do real, mas sim um objeto com uma narrativa, que coloca a história à disposição daquele que a conta e a organiza em modelos (AUMONT, 1995). Considera assim o cinema como um produtor de uma realidade de forma artificial. 
Com a convenção de que o cinema é um artifício fica também necessário reiterar que produções audiovisuais são, assim como as demais realizações e interações humanas, produtos do seu tempo, portanto, elementos criados e pensados de acordo com o período em que foram produzidos, para um espectador contemporâneo a eles, e que estes dois indivíduos (o que produziu e o que assistiu) têm em partes os mesmos códigos culturais e de linguagem (AUMONT; MARIE, 2004). Assim, cada filme é um artifício com características históricas singulares próprias. Como um produto de seu tempo, o audiovisual é também um elemento que contém em si muito da sociedade que o produziu e o vai receber, pois é um tipo de representação dos códigos que esta sociedade tem sobre si mesma (ROSENSTONE, 2010). Ele não é um espelho da sociedade, mas contém estes elementos que permitem análises.

Aumont e Marie reiteram o quão importante é analisar o cinema não somente fazendo uma crítica fílmica, mas também por um viés que busque uma compreensão de uma parcela de mundo daqueles que o produziram. $\mathrm{O}$ audiovisual contém elementos que atingem o espectador: sentimentos, temores e sonhos de seu tempo. É um elemento histórico, um possível meio para estudo de um período de balizas sócio-históricas de um período (AUMONT; MARIE, 2004: 5-8).

Assim, é importante considerar o cinema como um veículo de representações sociais, fundamentalmente levando em conta os determinantes técnicos e de linguagem que constroem esta representação. Tais pontos são a metodologia da produção cinematográfica, e, portanto, um possível meio de análise de um produto audiovisual (OLIVEIRA, 2008). 


\section{O gênero road movie}

Ao longo da história do cinema, seu desenvolvimento enquanto arte e indústria gerou a categorização de gêneros cinematográficos levando em consideração características estéticas e elementos narrativos específicos em cada caso (BERNARDET, 2006). Jacques Aumont e Michel Marie (AUMONT;MARIE, 2003: 142) frisam como a concepção de gênero em cinema sempre teve considerações hesitantes para sua definição.

O road movie é assim um gênero cinematográfico que comporta filmes de grande sucesso e tem um público cativo e um reconhecimentos dos elementos que compõe e são reconhecíveis na narrativa. A compreensão dos filmes enquanto pertencente a este gênero considera como objetos centrais para sua categorização principalmente três elementos, que são a estrada, o veículo e uma jornada, comumente interpretada como uma jornada para os personagens.

Com esta compreensão e tendo em mente a afirmação de Samuel Paiva sobre o caráter não-inato dos gêneros cinematográficos (PAIVA, 2011), ainda que possamos enxergar repetições entre os chamados road movies (ou em qualquer outro gênero cinematográfico), fazer parte de determinado gênero não significa seguir evoluções previsíveis, dado o fato que essas obras dialogam com contextos e personagens diversos e portanto, podem ter funções e expressar valores culturais igualmente heterogêneos. Assim, como afirma Samuel Paiva, 
Os gêneros propõem recorrentemente intertextualidades. Funcionam com uma lógica simbólica simples, capaz de abranger diferentes sujeitos em contextos distintos. Podem ter funções rituais ou ideológicas, envolvendo-se com as sociedades, as culturas e seus valores (PAIVA, 2011: 39).

Sobre os filmes precursores do road movie, Walter Moser (MOSER, 2008) ao considerar que todo gênero cinematográfico pode ser definido a partir de critérios formais, estéticos e sociológicos (entre outros), compreende em sua análise sobre o road movie fundamental relação entre o período histórico em que este gênero se desenvolve e suas características formais. Com um desenvolvimento industrial quase sincrônico, Moser relaciona a criação do automóvel à combustão e do cinema em fins de século XIX como um fenômeno essencialmente norte americano e fomentador deste gênero de cinema. O cinema e o automóvel são produtos ímpares no período sobre suas possibilidades, tendo como consequência de seu amplo alcance de público uma remodelação do imaginário coletivo do período, principalmente quanto à dimensão espacial e temporal (MOSER, 2008: 8). São assim, novos paradigmas na modernidade - no caso, de uma modernidade sólida como a proposta por Zygmunt Bauman (BAUMAN, 2001). Sólida porque, na concepção de Bauman sobre os dois tipos de modernidade existentes a partir do século XX - a modernidade sólida e modernidade líquida -, ele compreende que os referenciais históricos do período sobre conquista do espaço vinculados à concepção colonialista e imperialista são essencialmente reflexo de uma predominância do espaço sobre o tempo, diferentemente do que ocorre na modernidade líquida, em que o tempo se sobrepõe ao 
espaço, mudança possível por um elementos do desenvolvimento industrial que são as tecnologias ligadas à informática.

Nas raízes culturais do road movie, David Laderman pontua na tensão da ideologia euro-americana de expansionismo e imperialismo e no ideário de predestinação como temas notoriamente presentes em alguns filmes do gênero (LADERMAN, 1996). Ainda sobre as raízes culturais, para Laderman, são literárias as origens formativas do gênero, pontuada com o romance de Jack Kerouac, On the Road, lançado em 1955. Em On the Road, o veículo não é somente o principal meio de viagem, é essencialmente um meio de transformação dos personagens principais (LADERMAN, 1996: 42). Laderman reitera que o romance de Kerouac tem diversas críticas ao materialismo norte-americano, com tensões ideológicas sobre o life style, a situação pós-Segunda Guerra Mundial e a Grande Depressão. Tais tensões foram constantemente retrabalhados dentro do mise-en-scène de road movies das décadas seguintes.

Todavia, se faz necessário frisar que tais críticas sobre a situação norte-americana pós-Grande Depressão e a guerra fazem parte de uma discussão mais antiga, tendo já em romances e filmes contemporâneos às grandes crises um lugar central de discussão. Um caso deste cinema precursor dos road movies e inspirado em um clássico da literatura norte-americana, com uma temática essencialmente crítica à condição de um grupo social específico das décadas de 1930 e 1940, é justamente o romance As Vinhas da Ira, publicado em 1939 por John Steinbeck. 
Ainda que possamos, portanto, esperar pontos de desacordo quanto a definição e a origem dos road movies em termos gerais, compreendemos que road movies são filmes cujo fio condutor é uma viagem, comumente vista como fuga seja do espaço familiar ou do mundo do trabalho, mas que pode ser também uma necessidade, uma luta por um lugar de um indivíduo ou um grupo social. A mobilidade possibilitada pelo automóvel e a estrada relaciona-se neste sentido a locomoção física, mas também a exploração dos personagens de suas identidades frente ao âmbito da modernidade e suas crises e contradições, contestando e questionando o status quo e o modo de vida da sociedade em que estão inseridos. Walter Moser (MOSER, 2008) trabalha com a ideia de mobilidade apresentada pelo teórico Franco Moretti (apud MORETTI, 1987), em que o mover-se não significa somente um deslocamento geográfico: o movimento pode se configurar de diferentes maneiras e dentro de diversos sistemas sociais, podendo estar incorporado ao sistema econômico (seja na emancipação do indivíduo capitalista, ou na sujeição e luta do mesmo contra o sistema), como também na expansão colonial, mas não só. A mobilidade é cabível também dentro da configuração do sujeito moderno, uma vez que a modernidade compreende este último como aquele que se forma, se emancipa e é agente transformador de seu meio.

Citando Reinhart Koselleck, Moser mostra a historicidade desta relação entre mobilidade e indivíduo, pois segundo o primeiro, a aparição do trem é o elemento que, historicamente, provoca o maior choque de experiência quanto à relação entre tempo e espaço (MOSER, 2008: 9). O surgimento do automóvel à combustão por sua vez, datado de fins 
de século XIX, une duas fortes tendências da modernidade: a liberdade do deslocamento do indivíduo e a autonomia do sujeito individual. São elementos de compreensão de tempo e espaço que devem essencialmente ser ponderados em análises sobre modernidade, pois assim como o cinema, são produtos de massa - o fordismo é em Bauman ponto de análise crucial na definição de modernidade sólida - que afetam o comportamento das pessoas e suas maneiras de se situarem no mundo. Assim como o cinema desenvolvendo-se desde fins de século XIX modifica a compreensão de presença, imagem e a capacidade cognitiva do indivíduo, o automóvel à combustão é um dos emancipadores do homem moderno, e tem também sua significação no imaginário coletivo contemporâneo.

Discutindo esta compreensão de modernidade que tem o deslocamento e a temporalidade relativa dentro de suas implicações, essencial é nortear análises do gênero road movie pela premissa de que tal gênero tem em si filmes que são produtos de uma contingência histórica específica, em que cada roteiro mesmo contendo tipos centrais, tem uma inquietação própria que justifica a inter-relação dos mesmos (MOSER, 2008). Por esta razão, estes filmes tem sua estrutura estética e narratológica singular, que expressam as fragilidades e as instituições sociais do período em que foram produzidos, sendo todos elementos de uma ambiguidade existencial tipicamente moderna.

Como um gênero em construção a mais de 70 anos - considerando seus filmes precursores e seus filmes mais emblemáticos -, os road movies tem diversas temáticas e críticas histórico-sociais. Para Shari 
Roberts (ROBERTS, 1997: 45-69), o papel central essencialmente masculino dos primeiros road movies tem sua fantasia herdada dos filmes do gênero western de Hollywood, em que um ideal escapista majoritariamente masculino, tanto em sua concepção de liberdade quanto em seu simbolismo de fronteira - também masculino, individual e opressivo -, coloca a estrada e a viagem como uma fuga da esfera doméstica, no período do domínio feminino. Jessie Gibbs aponta como durante os últimos 50 anos, o gênero de road movie fez uma saída deste âmbito patriarcal e de raízes masculinas e que cineastas de todo o mundo têm usado o gênero como um veículo para a representação da alteridade: paródias subversivas do gênero podem dar um espaço para aqueles grupos sociais tradicionalmente marginalizados, em termos de raça, classe, gênero ou sexualidade (GIBBS, 2005).

O presente estudo buscou uma inflexão sobre a relação entre cinema e história a partir desta compreensão de que road movie é um gênero que comporta filmes utilizados para dar lugar a grupos sociais marginalizados e a ideais inovadores em seu tempo. Através de uma discussão sobre a formação do gênero de cinema road movie, propomos a partir do estudo de As Vinhas da Ira (1940), apresentar a formação do gênero e as temáticas tratadas no filme em sua relação com aspectos da história dos Estados Unidos na década de 1930 e início de 1940. 


\section{As Vinhas da Ira e seu pertencimento ao gênero: o deslocamento geográfico e de poder familiar da família Joad}

As Vinhas da Ira, em inglês The Grapes of Wrath, é um filme estadunidense do gênero drama, da Twentieth Century-Fox, com a produção de Daryl F Zanuck, um dos maiores produtores do cinema norteamericano do século XX. Inspirado no romance homônimo de John Steinbeck lançado em 1939, a adaptação de roteiro foi feita por Nunnally Johnson (aprovada previamente por John Steinbeck) e a direção é John Ford, um dos mais renomados cineastas da história do cinema norte-americano. Lançado em 15 de março de 1940 o filme também tem dois Oscars de 1941: de melhor direção para John Ford e de melhor atriz coadjuvante para Jane Darwell, a Ma Joad (GOSSAGE, 1990).

Para Vivian C. Sobchack, a característica que mais chamou atenção ao filme em seu lançamento foi, com certeza, seu parentesco ilustre: o filme foi inspirado no romance de maior sucesso dos últimos anos nos Estados Unidos daquele período e dirigido por John Ford, o grande nome dos filmes de western (SOBCHACK, 1979). O romance As Vinhas da Ira conta a saga da família Joad, que, como retrato de outras famílias de arrendatários que enfrentam a crise no campo da década de 1930, perde sua fazenda em Oklahoma para o banco e tem a estrada em direção à Califórnia como casa.

Uma das razões para o sucesso do filme, além do já citado parentesco ilustre, tem a ver com seus temas, contemporâneos àquela época. O lançamento do romance As Vinhas da Ira em 1939 e o lançamento do filme em 1940 foram simultâneos aos temas tratados nas duas obras, 
ainda que com certa diferença neste tratamento. Os efeitos da Grande Depressão e das tempestades de areia nas Grandes Planícies do Estados Unidos durante a década de 1930 (que ficaram conhecidas como Dust Bowl) são presentes ainda em 1940, ano de lançamento do filme (WORSTER, 1980).

Para analisar este filme, importante é salientar que ele se enquadra como um filme de road movie pois sua história se passa ligada a uma necessidade maior que é a viagem com destino a Califórnia, relacionada portanto, a estadia dos Joad no caminhão que os transporta até lá e o deslocamento permitido pela estrada. Compreendemos assim que este filme é representativo por ter os elementos do gênero road movie e também ser um filme que tem uma construção imagética e narrativa preocupada em documentar uma situação específica da história dos Estados Unidos, que é o deslocamento de contingentes migratórios desalojados por causa das Dust Bowl.

A viagem dos Joad para a Califórnia depende de um caminhão que entendemos como um recurso de linguagem fílmica, pois durante todo o longa-metragem os enquadramentos do automóvel para mostrar a família são sempre em plano aberto, sua imagem abarrotada por pessoas e pertences que demonstra o tamanho e a situação desta mudança. Os efeitos sonoros e visuais, como a fumaça que emana do automóvel durante toda a viagem, fazem parte da construção narrativa da jornada, pois o caminhão é um elemento determinante e essencial para a travessia do país. A análise deste elemento em específico (o automóvel caminhão para viagem, e o automóvel trator que substitui os Joad no campo 
como trabalhadores) demonstra a fragilidade da relação com o homem e o trabalho, o homem e a terra, o homem e a máquina: é um elemento que capacita a leitura de incidentes e relações históricas no enredo e de crises norte-americanas da modernidade da década de 1930 e 1940, como o desalojamento geográfico e a substituição da força de trabalho no campo.

Corroboramos assim a análise de Walter Moser (MOSER, 2008), pois consideramos que a narrativa de As Vinhas da Ira ao representar esta mobilidade por meio do caminhão se insere e se relaciona dentro destas crises da modernidade características da primeira metade do século XX. É no caminhão e pelo caminhão que os questionamentos dos Joad vão acontecer, e é ele que leva esta família para sua viagem que é igualmente entendida aqui em conjunto com a estrada (assim como em demais road movies, cada um em sua especificidade), como significador de uma mobilidade não só geográfica, mas também psicológica e social, rumo à fronteiras terrestres e identitárias dos personagens, de tal forma que o contingente histórico tem lugar no enredo também por este artifício. O caminhão e a estrada são a casa dos Joad por razão da situação histórica que a região das Grandes Planícies dos Estados Unidos e a economia mundial passavam, e a família deposita em um elemento moderno e em um novo pertence (o caminhão foi comprado usado para a viagem) suas esperanças para uma nova vida na Califórnia.

O simbolismo do automóvel e da estrada ficam ainda mais significativos nesta análise se pontuamos que a perda da fazenda - o espaço geográfico dos Joad - influencia na própria configuração de poder den- 
tro da família, mudança esta que acontecerá na estrada, no caminhão. Considerando a historicidade do período de produção do filme e a história dos Estados Unidos, podemos fazer uma interpretação e análise do longa-metragem que compreende que a dificuldade de cultivo do solo, a seca, os baixos preços pagos e as dívidas com os donos da terra são frutos do capitalismo liberal e do cultivo extensivo exigido durante a Era Progressista dos Estados Unidos (KARNAL, 2007), e que tem na década de 1930 seu esgotamento com as Dust Bowl e a Crise Econômica (WORSTER, 1980). Portanto, esta necessidade da partida e do abandono das vidas que estes fazendeiros tinham em Oklahoma e a posterior miséria em que vão viver é o ápice de uma situação que é maior do que o filme conta, evidenciada quando feita a análise e historicizando sua produção e seus produtores. O que a viagem simboliza e o que o caminhão significa são assim deslocamentos geográficos e de poder, reconfigurações desta família norte-americana que acontecem durante a viagem.

\section{Considerações Finais}

A análise fílmica considerando como elementos linguísticos a imagem, a narrativa, o som e a montagem permitiu analisar qual foi o processo de construção do significado da mobilidade, do automóvel e da viagem em As Vinhas da Ira, comportando interpretações de um momento histórico. O estilo visual do filme é próprio, privilegia as situações familiares em plano aberto, dando a visão do conjunto, e as situações de diálogo em close-ups demonstrando a emergência das ações e 
da situação. Compreendemos que As Vinhas da Ira é um road movie, e a utilização desta análise entre Cinema e História que dá conta de recortes específicos e da apresentação imagética, sonora e do papel na narrativa destes elementos, permitiu a interpretação do automóvel e do deslocamento e da fragilidade da relação com o a família e as consequências do viagem em sua configuração. Neste filme o automóvel (o trator e o caminhão) postam-se desta como um elemento que capacita a leitura de incidentes e relações históricas no enredo e de crises norte-americanas da modernidade da década de 1930 e 1940 além vão daquelas apresentadas por As Vinhas da Ira só por seu roteiro. A análise fílmica permitiu relações com a história e a leitura de crises não apresentadas diretamente no filme.

Como debate Moser, as discussões e readequações do indivíduo são parte do ideário de viagem nos road movies (MOSER, 2008). Compreendemos que em As Vinhas da Ira a ambientação da narrativa se passa toda ligada à estrada e ao caminhão que a família compra para esta viagem para a Califórnia, e ilustra a situação de miséria e de luta dos Joad para chegar ao seu destino, além de demonstrar a transformação interna desta família. Compreendemos que neste road movia a viagem simboliza para os Joad uma mudança na instituição familiar, pois é uma figura feminina quem os mantém unidos e quem toma a frente nas escolhas para os seus: a família Joad representa assim as mudanças que as famílias sofreram e sua perda de lugar social após a Dust Bowl, e este road movie é a jornada da transformação de um grupo social que os Joad representam. 
Assim, a perda da fazenda influência na própria configuração de poder dentro da família na medida em que Ma Joad passa a ter o lugar central, pois Pa Joad é um personagem nostálgico: ele não consegue deixar sua lembrança do que era sua família e sua terra, não consegue lidar com a modernização do campo; é preso e representa um passado anterior a Crise Econômica e a Dust Bowl. É Ma Joad que se desvencilha da configuração de sua família que vivia em Oklahoma e quem representa os valores da família americana que os mantém unidos, sendo a figura feminina neste filme que lida com a transformação do modelo patriarcal de família neste período Entre Guerras.

Como aponta Laderman, a tensão do movimento expansionista norte-americano é tema notoriamente presente em alguns filmes do gênero, principalmente nos westerns (LADERMAN, 1996). De acordo com esta constatação, a presente análise de As Vinhas da Ira entende o filme como um road movie que apresenta uma jornada singular da família Joad que cruza os Estados Unidos de Oklahoma até a Califórnia não para descobrir o oeste e povoá-lo, mas sim para procurar trabalho e uma nova condição de vida, sendo uma tensão presente no filme a da população norte-americana que assistia a esses contingentes migratórios sem aceitá-los, gerando até mesmo situações de preconceito e exclusão. Assim, As Vinhas da Ira é também uma construção narrativa da família Joad como representativa dos valores de resistência da família americana em face à Crise Econômica e aos desastres ambientais, de forma a defendê-los dos que não sofreram com a crise no campo, e, como aponta 
Moser (MOSER, 2008), da situação de não-pertencimento (geográfico e social) que norteiam a viagem e o deslocamento nos road movies.

\section{Fonte}

AS VINHAS DA IRA. Direção de John Ford. Estados Unidos, 1940. 1 DVD. Twentieth Century Fox Film Corporation. 129 min, preto e branco.

\section{Bibliografia}

AUMONT, Jacques; MARIE, Michel. Dicionário teórico e crítico de cinema. Campinas: Papirus, 2003.

AUMONT, Jacques (Et al). A Estética do Filme. Campinas: Papirus, 1995.

AUMONT, Jacques; MARIE, Michel. A Análise do Filme. Lisboa: Edições Texto \& Grafia, 2004

BAUMAN, Zygmunt. Modernidade líquida. Rio de Janeiro: Jorge Zahar, 2001.

BERNARDET, Jean-Claude. O que é Cinema. São Paulo: Brasiliense, 2006.

GIBBS, Jessie. Y tu mamá también: Road Movies Mapping the Nation. eSharp: Electronic Social Sciences, Humanities, and Arts Review for Postgraduates, vol. 4, pp. 1-13, Spring 2005.

GOSSAGE, Leslie. The Artful Propaganda of Ford's - The Grapes of Wrath. Harvard University - Widener Library, Cambridge. IN: WYATT, David. New Essays on The Grapes of Wrath. pp 101-126, 1990.

KARNAL, Leandro. História dos Estados Unidos: das origens ao século XI. São Paulo: Editora Contexto, 2007. 
LADERMAN, David. What a Trip: the Road Film and American Culture. Journal of Film and Video, Vol. 48, No. 1/2 (Spring-Summer 1996), pp. 41-57.

LAGNY, Michele. Cine y historia: problemas y métodos en la investigación cinematográfica. Barcelona: Bosch, 1997.

MOSER, Walter. Le Road Movie: un Genre Issu d'une Constellation Moderne de Locomotion et de Médiamotion. IN: Cinémas : revue d'études cinématographiques / Cinémas: Journal of Film Studies, vol. $18, \mathrm{n}^{\circ} 2-3,2008$.

OLIVEIRA, Dennison. O cinema como fonte para a história. In: Fontes históricas: métodos e tipologias, 2008, Curitiba. III Evento de Extensão em Pesquisa Histórica, 2008. p. 1-12.

PAIVA, Samuel. Gêneses do Gênero Road Movie. Significação: Revista de Cultura Audiovisual, v. 36, p. 35-53, 2011.

ROBERTS, Shari. Western Meets Eastwood: Subtext, Genre and Gender on the Road. IN: The Road Movie Book, ed. by Steven Cohan and Ina Rae Hark (London: Routledge, 1997), pp. 45-69.

ROSENSTONE, Robert. A história nos filmes / Os filmes na história. São Paulo: Paz e Terra, 2010.

SOBCHACK, Vivian C. The Grapes of Wrath (1940): Thematic Emphasis Trough Visual Style. American Quarterly, Vol. 31, No. 5, Special Issue: Film and American Studies (Winter, 1979), The Johns Hopkins University Press. pp. 596-615

WORSTER, Donald. Dust Bowl: The Southern Plains in the 1930's. Oxford University Press Inc, 1980. 